\title{
ARQUEOLOGÍA Y MEMORIA: LA GUERRA CIVIL EN EL SECTOR DE SAN ISIDRO (PUEBLA DE LILLO, LEÓN)
}

\author{
Eduardo GONZÁlez GÓMEZ DE AGÜERo - Víctor BEJEGA GARCÍA \\ Universidad de León
}

Recibido: 20/09/2012

Aceptado: 22/10/2012

\begin{abstract}
RESUMEN: El presente artículo sirve de presentación del Proyecto de Intervención Arqueológica en los restos de la Guerra Civil del Término Municipal de Puebla de Lillo (León), desarrollado en Septiembre de 2011. Los objetivos del proyecto eran ampliar la información sobre el conflicto en el Frente del Puerto de San Isidro, atendiendo a tres pilares: excavación, prospección/catalogación y divulgación. La combinación de los trabajos de excavación y prospección arqueológica y el estudio de fuentes periodísticas y orales, nos ha permitido ampliar la información correspondiente al desarrollo del Frente de San Isidro y las condiciones de la gente que lo vivió. En este trabajo presentaremos un primer acercamiento a los resultados del proyecto.
\end{abstract}

PALABRAS CLAVE: Arqueología del Conflicto, Frente Norte, Prensa, Guerra Civil.

ABSTRACT: This paper presents the Archaeological Intervention Project in the remains of the Spanish Civil War in North Front (Puebla de Lillo, León, Spain), developed in September 2011. The objectives of the project were to elaborate on the conflict in front of "Puerto de San Isidro", based on three concepts: excavation, survey and documentation, and dissemination. The combination of excavation and archaeological survey and study of journalistic and oral sources, has allowed us to expand the information for the development of front and conditions of the people who lived it.

KEYWORDS: Conflict archaeology, North front, Press, Civil War.

\section{INTRODUCCIÓN.}

El puerto de San Isidro está situado al noreste de la Provincia de León (ILUSTRACIÓN 1), siendo uno de los pasos naturales entre Asturias y León. Esta posición estratégica lo convirtió en uno de los puntos de enfrentamiento durante la Guerra Civil Española entre los años 1936 y 1937, siendo considerada como una zona secundaria dentro de la Guerra, tanto por los estrategas del momento, como por la investigación histórica posterior. Este vacío en los estudios, así como la 
creciente demanda por parte de la sociedad de recuperar los restos del conflicto bélico, dieron forma a la realización de este proyecto.

Ilustración 1. Localización del Sector de San Isidro

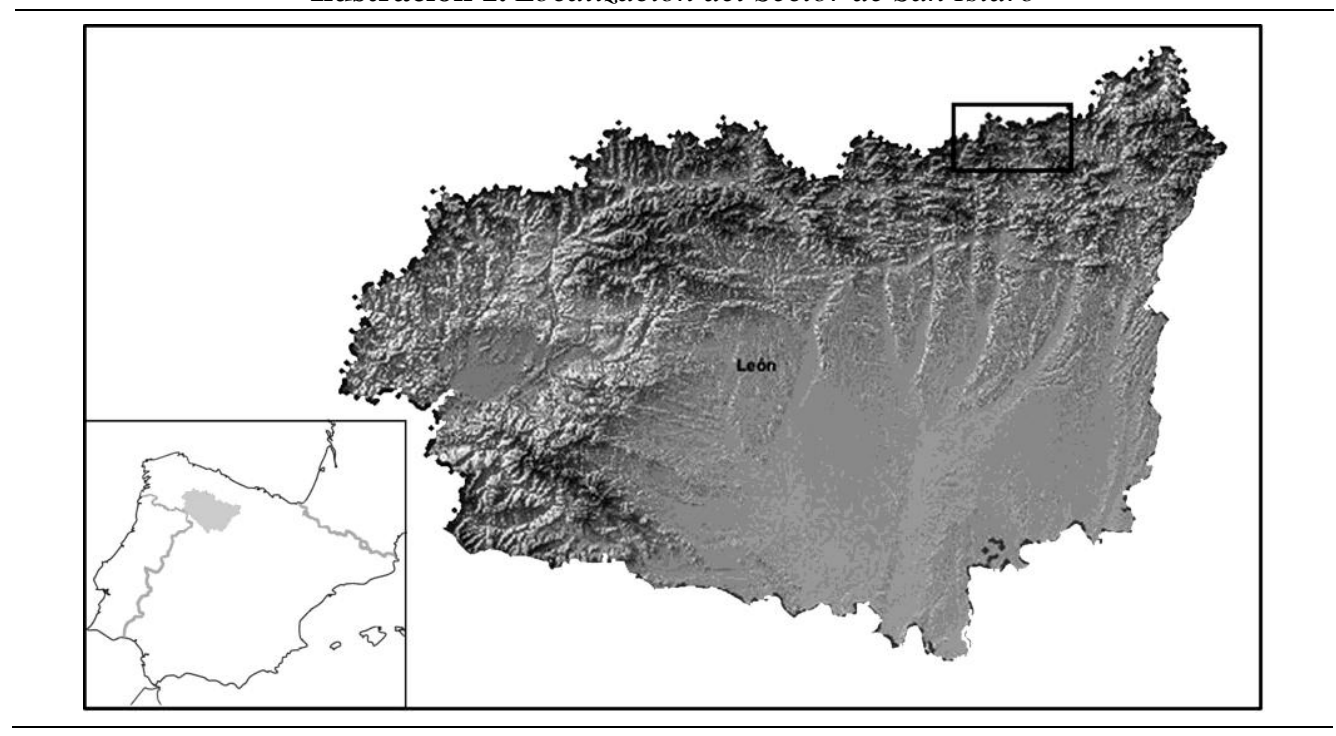

Los objetivos no son únicamente académicos, sino que se pretende promover la recuperación patrimonial y social, y para ello se realizaron diferentes actividades con la comunidad local, entre las que destacan jornadas de puertas abiertas, conferencias, así como la grabación de cortos documentales a cargo del grupo audiovisual $\mathrm{AV}^{1}$ y la difusión en los medios de comunicación. La intervención se integró dentro de los proyectos" ${ }^{2}$ : “Arqueología del Fascismo: Materialidad y Memoria", financiado por el CSIC, y "Ruin Memories Project" financiado por el Norwegian Reseach Council (Kulver Program), cuya dirección en España recayó

1 www.av2.es

2 Este proyecto pudo realizarse gracias al gran trabajo desarrollado por el equipo de arqueólogos (Xurxo Ayán, Carlos Marín, Juan Carlos Álvarez, Gonzalo Compañy y Javier Montoro), así como por el apoyo de Javier Rodríguez González y de Alfredo González Ruibal (codirector de la excavación), ya que sin su ayuda no hubiera sido posible realizar esta campaña. También tenemos que agradecer a los vecinos del Ayto. de Puebla de Lillo su acogida y colaboración, especialmente Juan Carlos Trevisón, José Fanjul, a Laudelino y Tina por la cesión de materiales, así como por la información ofrecida. Por otro lado, agradecer a la Junta Vecinal de Puebla de Lillo y a la Delegación Territorial de Medio Ambiente y a la de Patrimonio de León, por la concesión de las autorizaciones para realizar los trabajos arqueológicos. 
sobre Alfredo González Ruibal, que ha venido dirigiendo intervenciones de este tipo en España desde 2006.

Durante el trabajo de campo se prospectaron algunas de las posiciones localizadas en el Municipio de Puebla de Lillo, completando el proyecto con la realización de tres sondeos arqueológicos en el Cueto de Castiltejón, una pequeña posición avanzada republicana ${ }^{3}$. La documentación consultada y el trabajo con fuentes orales nos abrieron una nueva vía de estudio para interpretar el desarrollo bélico en la zona. Somos conscientes del carácter propagandístico que juega la prensa en el desarrollo de la guerra, del mismo modo que sabemos del carácter selectivo de la memoria como fenómeno cognitivo. Sin embargo, ambas se basan en hechos históricos, y una lectura crítica y combinada con otras fuentes de información, puede ayudarnos a entender mejor el desarrollo de un conflicto militar y social de esta envergadura, así como acercarnos al día a día de aquellos que vivieron y sufrieron la guerra.

\section{EL LEVANTAMIENTO MILITAR Y LA CONFIGURACIÓN DEL FRENTE.}

El golpe militar de 1936 conjuga los elementos típicos de los levantamientos militares de la España contemporánea, siendo la principal novedad la planificación simultánea y un rápido asalto al centro del poder. La primera fase de pronunciamientos tendrá lugar entre los días 17 y 21 de julio, fracasando en su principal objetivo, el rápido final de la República, lo que ocasionará la división del territorio entre rebeldes y republicanos, así como el inicio de la Guerra Civil ${ }^{4}$. En León el pronunciamiento estaba planificado para el 19 de Julio de 1936, aunque se verá retrasado por la llegada a la capital de voluntarios asturianos que se dirigían hacia Madrid ${ }^{5}$. Estos voluntarios saldrán de la ciudad tras ser armados con fusiles y ametralladoras. El día 20, tras alguna resistencia republicana en el Gobierno Civil,

3 Gonzalez Ruibal, A.; Bejega Garcia, V.; González Gomez De Agüero, E. (2011). Intervención arqueológica en los restos de la Guerra Civil del Término Municipal de Puebla de Lillo, León. Informe de las actuaciones arqueológicas. Informe depositado en el Servicio Territorial de Patrimonio Cultural de Castilla y León.

${ }^{4}$ Rodríguez GonZÁlez, J. (2003). León bajo la dictadura franquista (1936-1951). León: Universidad de León, p. 567.

Rodriguez GonZÁlez, J. (2007). «Guerra y represión en León», en Berzal De La Rosa, E. (Coord.), Testimonio de Voces Olvidadas. León: Fundación 27 de Marzo, pp. 151-214

5 Álvarez Oblanca, W.; Serrano, S. (2010). La Guerra Civil en León. León: Edilesa, p.400.

Álvarez Oblanca, W.; Serrano, S. (1987). «La Guerra Civil en León». Tierras de León, nº 67. 
en la Casa del Pueblo y en San Marcos, las fuerzas militares de León, La Virgen del Camino y Astorga se unirán a la sublevación ${ }^{6}$.

En la mayor parte de las comarcas agrícolas leonesas los sublevados se impusieron sin problemas pese a la existencia de importantes focos republicanos como Valencia de Don Juan, Sahagún, Valderas y Mansilla de las Mulas. En estos lugares, tras la lectura del bando de estado de guerra por parte de la Guardia Civil, los escasos falangistas tomaban el control de las poblaciones. Controlada la situación en los principales núcleos urbanos de la provincia, se establecen dos centros de actividad militar (León y Ponferrada) para controlar toda la cuenca del Esla y del Sil ${ }^{7}$.

La confusión de la población, la desorganización de los gubernamentales y la negativa del gobernador civil a repartir armas entre los leales, hacen que la resistencia sea muy dispersa, mal organizada y lenta en cuanto a la toma de decisiones $^{8}$. Esto contrasta con las fuerzas sublevadas, donde la estructura militar confería a sus movimientos un alto grado de coordinación. Estos factores van a ser claves a la hora de entender la toma de pueblos como Puebla de Lillo, como nos comentaba Laudelino?.

Desde el centro militar sublevado de León se realizarán diferentes incursiones a lo largo de los meses de julio y agosto con el fin de controlar los puntos clave de comunicación con Asturias. De este modo, desde el 26 de julio toman las poblaciones localizadas a lo largo del ferrocarril de la Robla ${ }^{10}$ mediante un avance muy rápido, ocupando el día 27 de julio Cistierna y seguramente Boñar, lo que va a facilitar el acceso de los rebeldes a Puebla de Lillo fruto en parte de esa confusión inicial $^{11}$. Esta zona presentaba gran importancia estratégica, ya que allí se bifurca la

${ }^{6}$ RodrígueZ, op.cit.; Álvarez OBlanCA et al.,op.cit; SAlAS LARRAZÁBAL, R. (1986-87). «León en la Guerra del Norte». La Guerra Civil Española en León. Ed. Diario de León, pp. 417-432.

7 SAlas LarrazÁBal, op. Cit.

${ }^{8}$ En las primeras comunicaciones radiofónicas rebeldes en León sonaban Vivas a la República y el Himno de Riego (Álvarez Oblanca y Serrano, 1987: 57).

${ }^{9}$ Laudelino Sánchez, de 88 años de edad, es natural de Puebla de Lillo, aunque actualmente vive en Cofiñal. Le fueron realizadas dos entrevistas: una el día 7 de septiembre de 2011, de la que no pudimos hacer grabación, y otra el día 8 de septiembre de 2011, registrada mediante grabación de video y audio.

${ }^{10}$ Salas Larrazábal, op. Cit.

11 "Cuando estalló la guerra, hubo tres o cuatro días que no se sabía nada. Los de la junta mandaron a mi hermano Teodoro, que tenía diecisiete años, en bicicleta, a informarse a Boñar. Allí ya le dieron un litro de aceite de ricino. En septiembre fue el primer ataque”. (Laudelino Sánchez, 07-09-2011). 
carretera que comunica Asturias, por medio de los puertos de Tarna y San Isidro, con la León-Valladolid a través de Boñar.

Si bien a finales de julio de 1936 los sublevados en la montaña oriental controlaban los pueblos que daban acceso a las zonas de alta montaña de la cordillera, todavía tardarían un mes más en llegar a los puertos. Este freno en el avance sublevado podría deberse al escaso número de efectivos con los que contaban en León ${ }^{12}$ y a los acontecimientos que estaban teniendo lugar en la montaña occidental. Así, la necesidad de apoyar a Aranda y levantar el sitio de Oviedo, supuso que gran parte de los efectivos militares se centraran en enlazar Villablino con León ${ }^{13}$.

El ejército republicano también va a centrar su actividad militar en la zona de Oviedo, sin que se produzca la configuración de un frente y un ordenamiento de las tropas republicanas en la zona oriental asturleonesa. Hasta el 26 de agosto de 1936, con la creación en Busdongo del Comité provincial de Milicias Antifascistas Leonesas, era común la aparición de numerosos Comités Unitarios y Comités de Guerra que dispersaron los efectivos republicanos. Debido a los factores comentados anteriormente, la resistencia republicana va a estar formada, inicialmente, por pequeños grupos de hombres armados.

Puebla de Lillo será tomada el 21 de agosto por una centuria de Falange procedente de Maraña y Riaño ${ }^{14}$ sin encontrarse ningún tipo de resistencia ${ }^{15}$. Las tropas llegaron mientras los vecinos se encontraban en el salón social por la noche, escuchando en la radio los partes sobre el desarrollo del golpe de Estado ${ }^{16}$. Sobre el 26 del mismo mes, para aliviar la presión ejercida por los sublevados en la zona

${ }^{12}$ Según Salas Larrazábal en agosto de 1936 la provincia de León contaría con 9.456 hombres de los cuales 4.195 estaban en retaguardia (1986-87: 414).

${ }^{13}$ RodríGUeZ, op. Cit.

14 Alvarez Oblanca et al., op. Cit.

15 "No hizo falta dar ningún tiro, pues los simpatizantes de izquierdas huyeron hacia la zona republicana próxima". AsOCIACION POZO GRAJERo (Ed.) (2008). La memoria del Grajero. Ministerio de la Presidencia del Gobierno.

16 "Eran las 10 cuando daban el telediario, y estaba lleno del pueblo por a ver que había, claro, era el acontecimiento. Yo estaba en el descanso con un paisano y sacó el reloj y dijo "coño ya son las diez", y digo: "mira ahi están ya", eran los falangistas, venían al mando de un capitán, y vinieron por Maraña, entraron por la parte de Las Nieves, de Redipollos, no había resistencia, eran vecinos los que estábamos allí. [...] La gente se marchó corriendo para Asturias por el miedo claro". (Laudelino Sánchez, 08-09-2011). 
occidental, se producirán varios ataques republicanos en las zonas centrales y orientales, entre ellos en el sector de Puebla de Lillo ${ }^{17}$.

La localización del centro de actividad militar en el entorno de Oviedo dará un periodo de tranquilidad en el resto de sectores, lo que aprovecharán los ejércitos para reorganizarse. En el bando sublevado se establecieron siete sectores que pervivieron durante el invierno y la primavera de 1937, estando formado uno de ellos por Boñar y Lillo. Por parte de los gubernamentales se unificará la dispersión de poderes creando el Consejo de Asturias y León, así como el Cuerpo de Ejército de Asturias, que se constituye en comandancias, entre ellas la de Cangas de Onís, encargada de la defensa del Puerto de San Isidro ${ }^{18}$.

El día 6 de septiembre ${ }^{19}$ un grupo de republicanos, entre los que se encontraban una trentena de huidos de Puebla de Lillo, van a intentar tomar esta localidad. Para frenar esta ofensiva parece que fue necesaria la llegada de refuerzos provenientes de León, consiguiendo los gubernamentales ocupar algunas casas y llegar hasta el Torreón con un "lanza bombas de madera" ${ }^{20}$. La necesidad de refuerzos por parte de los sublevados para defender la posición, estaría reflejando la presencia de un número muy limitado de tropas de ocupación en los pueblos, así como el alto nivel de organización de los rebeldes frente a los republicanos, lo que será clave en los primeros compases del conflicto. Según se desprende de la crónica del Diario de León ${ }^{21}$, existirían varios puntos de control en el pueblo, aunque es posible que no hubiera todavía una infraestructura defensiva como para hablar de un frente definido.

Esta operación va a marcar definitivamente las áreas de influencia de ambos combatientes, así como las futuras acciones militares en el sector. De este modo, durante los siguientes meses la actividad militar en Lillo se caracterizó por la

${ }^{17}$ AlVAREZ OBLANCA et al., op.cit.

${ }^{18}$ Salas Larrazábal, R. (2006) Historia del Ejército Popular de la República. La Esfera de los Libros.

${ }^{19}$ Diario de León. 07-09-1936: 5.

20 "En septiembre dieron un ataque los republicanos, metieron un aparato de madera, que yo lo vi, hasta el torreón, y allí pues cogieron a tres que venían con ellos, los mataron allí y unos chavales los enterraron. Uno decían que lo mataron porque traía un pantalón de Guardia Civil y que había matado a un Guardia Civil. [...] Uno de los que mataron era el famoso Requejo, tenía discos imprimidos, eran de Moreda. Y ese Requejo pues sí cantó y por la mañana lo mataron" (Laudelino Sánchez, 08-09-2011).

21 "A las tres de la madrugada, unos MIL mineros distribuidos en tres columnas, atacan el pueblo y guardias establecidas, en direcciones distintas y por los puntos más débiles" (Diario de León 07-09-1936: 5) 
acción de escaramuzas entre ambos bandos, pero sin que se produjera un enfrentamiento frontal de los dos ejércitos. Algunas de las principales operaciones llevadas a cabo por los republicanos de la montaña oriental leonesa fueron el abastecimiento de armas y víveres. Entre estas acciones parece que fue común la confiscación de ganado, teniendo estos actos una considerable repercusión en la prensa leonesa del momento.

El día 18 de septiembre de 1936 el Diario de León recoge el "robo" de rebaños de ovejas merinas en diferentes puertos de la montaña oriental leonesa. Sin embargo, lo más destacable de la noticia es la idea que se tenía, o se quería transmitir, del enfrentamiento, esperando una rápida solución del mismo. La mayor preocupación del autor del artículo son los "muchos propietarios de rebaños que se verán arruinados, y los pueblos montañeses que obtenían importantes ingresos por el arriendo de los puertos, amenazados de no cobrarlos, no solo este año, sino en venideros", cuando la verdadera ruina se produjo durante el siguiente año con la estabilización del frente. Por otro lado, es interesante ver como en la misma página se reflejan preparativos para una guerra larga con la colecta de dinero para la compra del Avión "León".

En cuanto a las tropas que se encontraban en este momento alojadas en Lillo, parece que la inactividad empezaba a hacer mella ${ }^{22}$. La propaganda oficial, difundida entre otros medios por la prensa de la época, fomentaba una sociedad en la que se recompensaba y castigaba públicamente a sus partidarios y a sus enemigos $^{23}$, además de valorar positivamente el sacrificio personal, incluso la muerte, por un fin mayor: "la salvación de la patria" 24 . La falta de efectivos, junto con la entrada en un territorio mucho más escarpado y mejor defendible por unas

22 “Con qué alegría, con qué valor y entusiasmo, hemos salido el otro día de el frente de Lillo, ilusionados con ir hacia nuevos y más gloriosos triunfos, que traerían a nuestra querida España días de paz y prosperidad, de gozos y alegrías. [...] todos ansiamos lo mismo, todos queremos que los camiones que nos han de conducir salgan lo antes posible hacia el punto en que hemos de principiar la campaña contra la caterva marxista" (Diario de León, 28-10-1936). Este artículo está escrito por Santiago Gago Alonso, falangista de la Primera escuadra de la segunda Falange de Lillo.

${ }^{23}$ Rodriguez GonZÁleZ, J. (2007) op.cit.

24 "[...] Sacrificio tenaz, perseverante, voluntario y general es en lo que hemos de inspirarnos, para cuando el honor y la integridad, la libertad y el decoro de la nación, así como el de los que luchan por esos postulados, den cima a sus tareas y su sangre generosa no vaya a ser estéril, sino fructífera, mostrándoles al mismo tiempo con nuestras aportaciones cuanto tenemos que agradecerles". Artículo del Gobierno Civil de León publicado el 28 del 11 de 1936 en la página 05 del Diario de León. 
tropas republicanas, de las que tampoco tenían noticias exactas de sus fuerzas, podría haber sido el motivo que frenará el avance rebelde ${ }^{25}$.

Las incursiones hacia Isoba van a ser habituales, convirtiéndose en maniobras para subir la moral, además de evitar la ociosidad de las tropas inactivas. Esta hipótesis parecen corroborarla varias noticias aparecidas en la prensa de la ciudad de León y que recogen estas operaciones. Como en estas maniobras era común la ausencia de enfrentamientos y no era posible el avance, se van a utilizar para motivar a las tropas atribuyéndoles "grandes logros" como la recuperación de una talla de la Virgen "maltratada" por los republicanos ${ }^{26}$.

\section{LA ESTRATEGIA DE FORTIFICACIÓN.}

En octubre de 1936 el pueblo de Isoba ya habría sido abandonado, quedando configuradas las áreas de control de ambos ejércitos, así como la aparición de un frente propiamente dicho. Según parece, a mediados de este mes ya se han realizado los primeros trabajos de fortificación con diversos parapetos ${ }^{27}$. A este respecto debió jugar un papel fundamental la reorganización de los republicanos en el norte, así como la llegada del invierno y la percepción de que el conflicto duraría más de lo que parecía. De este modo, el 29 de Octubre de 1936 el Ministerio de la Guerra del Gobierno de la República, aprueba el Decreto no 244 que supone el comienzo de la fortificación, movilizando a los hombres entre 16 y 45 años para realizar estas labores ${ }^{28}$.

La fortificación del sector de Puebla de Lillo va a verse condicionada en gran medida por la orografía del valle del Río Silván. El amplio valle de este río está flanqueado por crestones cuarcíticos que conectan geológicamente con el Puerto de Tarna. La erosión de ríos como el Silván han formado un vaciado de pizarras carboníferas que forman valles planos, rasas y depresiones agudas, dando lugar a estas gargantas de rocas más altas y duras ${ }^{29}$. Esta formación geológica va a definir

25 "[...] comprendiendo que era absurdo exponernos inútilmente desconociendo la situación marxista creyendo acaso que todo esto sería una emboscada, determinó nuestro regreso a Lillo [...]" (Diario de León 28-11-1936).

${ }^{26}$ Diario de León 18-10-1936; 28-11-1936; Proa 24-11-1936

${ }^{27}$ Diario de León 16-10-1936: 6.

28 "Cuando la fortificación se realizaban en primera línea de frente, solía desarrollarse durante la noche" (ASOCIACIÓN POZO GRAJERO, 2008).

29 Hernandez Sampelayo, P. (1941) «Los criaderos de talco de Lillo (León)». Notas y Comunicaciones del Instituto Geológico y Minero de España, N.8, pp.3-48; RodríGuEz Perez, C. (1995) «Estudio geomorfológico del Puerto de San Isidro». Eria, 36, pp. 63-87. 
el frente militar entre el Puerto de San Isidro y el Puerto de Tarna, ya que las posiciones militares se localizan en las zonas altas de estas formaciones.

En cuanto al sistema defensivo republicano, va a seguir los principios estratégicos que definen la fortificación gubernamental durante la guerra ${ }^{30}$. En el sector que nos ocupa se configurará en tres líneas de fortificación que controlaban el acceso por carretera a los puertos de San Isidro y Las Señales ${ }^{31}$ :

a) Posiciones avanzadas: Estarían conformadas por las trincheras del paraje de Las Fuentes y la Posición de Castiltejón, que controlan el acceso al puerto de San Isidro por carretera. En Castiltejón se localizaron varios refugios, puestos de tirador y un importante entramado de trincheras, además de un puesto de observación. Aunque por el momento no hemos localizado más posiciones avanzadas en este tramo de frente, es posible que cerca de Cofiñal, por debajo del Viular, existan más con estas características.

b) Línea de frente: Situada entre Peña Lázara y el Pico de la Granda hasta Cofiñal, con diversas estructuras que establecen una línea continua de frente. Las posiciones localizadas serían: Peña Lázara, con parapetos, casamatas y refugios construidos con muros de caliza aprovechando los afloramientos rocosos; Minas de Talco, formadas por varios parapetos con unas características similares a las de Peña Lázara; La Granda con parapetos, refugios de piedra, pozos de tirador y trincheras en la cresta, así como una galería de hormigón que da acceso a dos casamatas circulares del mismo material que serían utilizadas para el establecimiento de un arma automática tipo Colt Mod. 1895/1914 ${ }^{32}$. Finalmente en dirección a Cofiñal se encontrarían las trincheras de Valerianes y el Viular.

c) Retaguardia: Justamente detrás de estas posiciones se han localizado varios conjuntos conectados con la línea de frente y que servirían para dar descanso a los soldados. Una de estos complejos se encontraría detrás de las posiciones de Minas de Talco, aprovechando los edificios y el polvorín de estas explotaciones mineras. El otro gran complejo se encontraría en menor medida en Valerianes, Peña Lázara y La Granda con varias estructuras

${ }^{30}$ CAstellano Ruiz De La Torre, R. (2004). Los restos del asedio. Fortificación de la Guerra Civil en el Frente de Madrid. Ejército Nacional. Madrid: Almena Ediciones, p. 256.

${ }^{31}$ GonZalez Ruibal et al., op.cit.

32 Feito Alvarez, F.; Mortera Perez, A. (2009) «Tipología de los emplazamientos para armas automáticas en las fortificaciones asturianas de la Guerra Civil». Casamata, no2. ARAMA 36/37, pp. 11-19. 
circulares, cuevas y algún refugio, y principalmente en el Viular, donde se documentaron más de catorce estructuras en negativo pertenecientes a letrinas y refugios. En este punto además se localizó bastante material relacionado con la cocina de alimentos, por lo que es posible que existiera una cocina de campaña. A este entramado habría que incluir el pueblo de Isoba donde se encontraría uno de los puestos de mando.

En cuanto al ejército franquista, la configuración del frente va a ser totalmente diferente. La concepción de una guerra de avance frente a la guerra de fortificación republicana, así como al abandono de la línea de trinchera-abrigo continua, propia de la I Guerra Mundial, van a explicar este fenómeno. Desde el comienzo de la guerra entre los sublevados se tiene consciencia de lo inadecuado de este sistema en el conflicto moderno, por lo que ya en febrero de 1937 se distribuye entre los Jefes de Batallón instrucciones al respecto. Solamente se fortificaría en aquellas zonas de frentes defensivos donde la presión enemiga era fuerte ${ }^{33}$. Por otro lado, las propias características del terreno van a influir en que prácticamente no exista una fortificación importante.

Las posiciones que ocupaban los rebeldes se situaban en la Sierra de Rebollares y en el Cerro del Canto, dominando el norte y el este de Lillo. En Rebollares pudimos localizar una serie de parapetos en el sitio conocido como Cerro de la Cruz, sobre el pueblo, y que podrían estar relacionados con una posición de armas automáticas que controlaría el Cerro del Canto y la entrada a Lillo ${ }^{34}$. Estos parapetos del Cerro de la Cruz es posible que sean uno de los primeros elementos defensivos de los sublevados, ya que tenemos constancia de su existencia en octubre de $1936^{35}$.

Ya en el Pico del Águila se documentaron dos estructuras circulares realizadas con piedra de la zona y pozos de tirador, todos orientados hacia las posiciones republicanas al otro lado del valle. También se documentó una galería excavada en la roca que va a dar a un parapeto, posiblemente utilizado como punto de observación. Estas estructuras se ciñen bastante bien a lo definido por las normas de febrero de 1937, con la fortificación de determinados puntos como nidos de

33 Sequera Martinez, L. (2001). Historia de la fortificación española en el siglo XX. Salamanca: Fundación Caja Duero, p. 317; CASTEllano Ruiz DE LA TorRe, R. (2004) op.cit.

${ }^{34}$ Gaspar, A. (1937) Libro diario del Batallón de Infantería no ${ }^{\circ} 267$. Cangas de Onís, 20 de Abril de 1937.

35 Diario de León, 16-10-1936: 6. 
ametralladora y fusil, sin posiciones militares en las cumbres y la creación de observatorios en posiciones de vanguardia, así como la colocación de alambradas ${ }^{36}$.

\section{LA OFENSIVA DE MAYO.}

La llegada del invierno consolidó el sector, bastante inactivo militarmente, pero de una gran importancia estratégica. La propia orografía y climatología de la zona no facilitó las operaciones de avance por parte de ambos ejércitos, valorando más no perder terreno que ganarlo, y centrando sus esfuerzos en mantener la moral en los soldados que luchaban contra el duro invierno. Este panorama cambió en mayo, cuando los republicanos intentan tomar Lillo.

En mayo de 1937 el ejército republicano planifica una nueva operación que le acerque hasta León, y que involucrará a todo el frente desde La Robla hasta La Uña $^{37}$. En el Puerto de San Isidro la operación comenzó el día 11 de mayo con la llegada a Isoba del Batallón 267, que se uniría al 211 y al 241, llegando posteriormente el $227^{38}$. La maniobra dio comienzo el día 14, partiendo las tropas de dos puntos: 1) Las posiciones de Minas de talco, desde donde tomarían la Sierra de Rebollares. 2) Trincheras sobre Cofiñal, encargadas de tomar el Cerro del Canto. El principal objetivo de esta operación era ocupar estas posiciones para incomunicar Lillo con Boñar, así como imposibilitar la llegada de refuerzos desde León $^{39}$, sirviendo de maniobra para aliviar la presión sobre el País Vasco. Según se desprende del Diario del Batallón 267, esta operación tuvo varios fallos de organización y ejecución, además de importantes diferencias en los abastecimientos entre ambos ejércitos como comentaremos más adelante.

La importancia de esta operación queda patente en la repercusión a nivel nacional que tuvo, apareciendo la crónica en varios periódicos como el $\mathrm{ABC}^{40}$ y la Vanguardia ${ }^{41}$. La maniobra se inició por la mañana, pese a las malas condiciones climatológicas, con la cobertura de la artillería de $10,5 \mathrm{~mm}$. En un principio supuso un gran éxito, cercando el pueblo de Lillo y controlando la carretera de Boñar, aunque no se logra consolidar totalmente estas posiciones. De hecho, un parte del

\footnotetext{
${ }^{36}$ Diario de León, 17-05-1937; CASTELlano RuIz De LA TORRE, op.cit.

${ }^{37}$ SALAS LARRAZÁBAL,op.cit.

${ }^{38}$ GASPAR, op.cit.

${ }^{39}$ Diario Avance, 16-05-1937:6.

${ }^{40}$ Diario ABC, 15-05-1937:8.

${ }^{41}$ Diario La Vanguardia, 15-05-1937:6.
} 
ejército franquista de ese día ${ }^{42}$, así como el diario de operaciones del Batallón 267 hablan del "abandono de las posiciones tomadas por la acción del fuego enemigo" ". Durante el día siguiente se ocuparán de nuevo y se intentará avanzar, si bien llegarán refuerzos franquistas y la artillería. La llegada de tropas y la presión sobre Lillo lleva a los sublevados a lanzar un contrataque ${ }^{44}$ que obliga a replegarse a los republicanos. El día 16 comenzó a actuar la aviación sobre las posiciones republicanas, bombardeando la vanguardia y la retaguardia de Isoba ${ }^{45}$. La ausencia de referencias a combates de las tropas rebeldes para llegar a Lillo, hacen que se nos plantee la duda del control efectivo por parte del ejército republicano de la carretera de Boñar.

En estos primeros días de la operación los republicanos llegaron a tomar el Pico del Águila, donde tenían "fuertes posiciones de defensa los fascistas" "46 algunas de ellas documentadas durante la prospección junto con restos de granadas Laffite empleadas en los combates. Después de varios días de lucha, y agotado el factor sorpresa que llevó a un rápido avance por parte de los gubernamentales, se empiezan a estabilizar las posiciones, que para el día 17 parece que ya se encuentran fortificadas ${ }^{47}$. Durante la prospección, pudimos constatar la presencia de dos tramos de trinchera en zig-zag con dirección norte-sur, separados por unos $500 \mathrm{~m}$, que podrían corresponder al avance republicano y a esta fortificación.

Ante la posibilidad de perder Lillo, los rebeldes envían una columna de refuerzo constituida por dos grupos: el primero, conducido por el teniente coronel Pablo Arias Giménez, jefe de la Mehala de Gómara y el comandante Miguel San Martín del $7^{\circ}$ Tábor de Larache; y el segundo formado por reservas del sector, mandadas por el comandante Julián Gómez $\mathrm{Seco}^{48}$. Estas tropas parece que llegaron a Lillo sobre el 18 de mayo, desviándose de los frentes del País Vasco ${ }^{49}$. Ese día se produce un nuevo ataque republicano en el Pico del Águila que avanza hasta llegar a $300 \mathrm{~m}$ del pueblo, afirmando algunos vecinos que llegaron a ocupar las primeras

42 Garate Cordoba, J.M. (1978). Partes oficiales de Guerra, 1936-1939. Ejército Nacional. TOMO I. Madrid: Librería Editorial San Martín, p.480.

${ }^{43}$ GASPAR, op.cit.

${ }^{44}$ Diario de León, 17-05-1937.

45 Diario $A B C$, 18-05-1937.

${ }^{46}$ Diario Avance, 16-05-1937.

47 Diario ABC, 18-05-1937; GARATE CóRdobA, J.M. (1978b). Partes oficiales de Guerra. 19361939. Ejército de la República. TOMO II. Madrid: Librería Editorial San Martín, p.510.

${ }^{48}$ SALAS LARRAZÁBAL, op.cit.

${ }^{49}$ Diario ABC, 19-05-1937:7; Diario Avance, 19-05-1937:6. 
casas, pero la falta de munición obliga a las tropas a replegarse ${ }^{50}$. Desde este momento se producirán durísimos combates ${ }^{51}$, frenándose el avance republicano que día a día irá perdiendo terreno. Según los testigos, "la toma de estas posiciones supone la pérdida de una gran cantidad de soldados moros" $" 52$, que llegan incluso a sublevarse ante la elevada mortandad de sus compañeros. Finalmente, y gracias al apoyo de la aviación alemana y a las baterías artilleras, las tropas moras consiguen tomar las posiciones de Rebollares.

Ya el día 20, sufriendo considerablemente las tropas de Lillo por mantener las posiciones tomadas, se detectan movimientos en el sector de La Vecilla ${ }^{53}$, si bien en el Sector de San Isidro la ofensiva se ve frenada por el mal tiempo ${ }^{54}$. Durante los días siguientes los republicanos perderán las posiciones tomadas ${ }^{55}$, aunque, según algunos autores, la toma definitiva del Pico del Águila no se haría efectiva hasta el día $31^{56}$.

Estas operaciones retrasaron la configuración del VIII Cuerpo del Ejército que sería aprobada por Franco el 15 de mayo de 1937, correspondiendo la 81 División a la de León. En un primer momento no pasaron de un cambio de nomenclatura, pero con el incremento de las fuerzas se retocó la organización formando tres agrupaciones que cubrieron los sectores oriental, central y occidental, divididas en nueve subsectores, estando al mando del de Lillo al capitán Álvarez Crespo. Como consecuencia de esta ofensiva, las tropas moras que habían sido desviadas del frente vasco, quedarían en los frentes asturianos como brigada móvil ${ }^{57}$.

Por su parte, los republicanos tras la caída del País Vasco y las derrotas en el norte, pasaron el 6 de agosto a reorganizar el ejército, integrándose totalmente en el Ejército Popular de la República. De este modo el antiguo III Cuerpo, o asturiano, se dividirá en dos, el XVI que cubriría el Frente Leonés y el XVII el Asturiano. La caída de Santander debilitó considerablemente las tropas de la XVI, por lo que fue necesario un nuevo reajuste, constituyendo el 31 de agosto cuatro divisiones con lo

${ }^{50}$ GASPAR, op.cit.

${ }^{51}$ Diario Avance, 21-05-1937:6.

52 "Yo me acuerdo de lo de la Peña del Águila, alli los moros caían como chinos. Los cuerpos de los muertos de la batalla se guardaban en la cochera de mi padre, yo recuerdo haber contado unos cuarenta un día que entré alli’” (Laudelino Sánchez, 7-9-2011).

53 Diario $A B C, 20-05-1937: 7$.

${ }^{54}$ Diario Avance, 21-05-1937:6.

55 GASPAR, op.cit.

56 SALAS LARRAZÁBAL, op.cit.

57 SALAS LARRAZÁBAL, op.cit. 
que quedaba de las tropas vascas, asturianas y la antigua XVI. Estas brigadas cubrían hasta el puerto de San Isidro, donde se encontraban la 188 brigada y lo que quedaba de la 176 montañesa, defendiendo el frente desde este puerto hasta San Glorio.

Durante el mes de agosto tendrán lugar nuevas labores de fortificación en el frente, construyéndose el Fortín de Alboleya sobre la carretera que sube a Isoba, junto al lago del mismo nombre. Esta estructura está compuesta por dos tramos de galería cubierta de hormigón con unas catorce aspilleras por tramo y unidas entre sí por una galería excavada directamente en la roca ${ }^{58}$. Esta posición se localiza detrás de Peña Lázara y Minas de Talco, al fondo del Valle, por lo que se crea una tercera línea defensiva en el acceso al puerto de San Isidro. El ejército franquista, por su parte, coloca una alambrada electrificada en la bifurcación de la carretera hacia los puertos de San Isidro y Tarna.

Desde la ofensiva de mayo la actividad de la aviación y de la artillería se va a intensificar en el sector de Lillo, realizándose bombardeos en las inmediaciones del puerto de San Isidro cada dos o tres jornadas ${ }^{59}$. Fruto de estos bombardeos creemos que puede deberse la destrucción del refugio de hormigón localizado en la cima de Castiltejón. Este refugio estaba conectado con una trinchera y presentaba una plancha de hormigón de muy mala calidad de más de medio metro de espesor y sin ferralla. Su destrucción parece que ocurrió durante la guerra, ya que se volverá a ocupar como refugio durante el conflicto, realizando una techumbre sobre un entramado de madera.

\section{LA CAÍDA DEL SECTOR DE LILLO Y EL FIN DEL FRENTE.}

La existencia en el norte de un territorio fiel a la República significaba un problema para los sublevados, ya que les obligaba a dividir sus tropas y les privaba de importantes recursos en poder republicano ${ }^{60}$. Por otro lado, existía un miedo permanente a no poder frenar una incursión republicana a la Meseta y Galicia debido al poder del ejército asturiano. En marzo, después de la derrota sublevada en Guadalajara, Franco comprende que para ganar la guerra es necesario tomar todos los territorios, por lo que decide atacar el norte con una maniobra de este a oeste. De este modo el 19 de junio cae Bilbao, y el 26 de agosto Santander. El 9 de

${ }^{58}$ GONZALEZ RuiBAL et al., op.cit.

59 GonZalez Álvarez, M. (1986-87). «El aeródromo de León: la Legión Cóndor». La Guerra Civil Española en León. Ed. Diario de León, pp.433-448.

${ }^{60}$ RoDRIGUEZ, op.cit. 
junio de 1937 Franco se presentó en León para dar instrucciones a sus militares y dar una rápida solución al frente norte ${ }^{61}$.

La operación definitiva se iniciaría en septiembre de 1937 con una maniobra envolvente coordinada desde tres puntos: Solchaga entraría por la costa, Aranda tomaría los puertos de la cordillera astur-leonesa, y Muñoz Grandes entraría de sur a norte por la zona del Pontón hasta Cangas de Onís ${ }^{62}$. Dentro de este esquema el sector de Lillo y Tarna jugarían un papel crucial. Las primeras maniobras tuvieron lugar a principios de mes en la zona de la costa, siguiendo desde el 9 de septiembre en el sector central leonés que es barrido de oeste a este. El mismo día, el ejército republicano se vuelve a reorganizar, pasando el Puerto de San Isidro a formar parte de la División D, si bien a los pocos días volvería a abandonarla para integrarse en la Brigada autónoma 188 que cubriría el frente hasta San Glorio. Al iniciarse la ofensiva se realizará una nueva organización del ejército republicano del norte, la 188 brigada pidió refuerzos, enviándoles a los Batallones 212 y 222, que con el 241 formaron la Agrupación de San Isidro a cargo del mayor de milicias Silvino Morán. El 22 de septiembre las tropas sublevadas tomaron Villamanín y Cármenes, asegurado el puerto de Pajares y dando paso a las maniobras del sector de Lillo y Tarna.

Como vimos anteriormente, la configuración orográfica del valle de los ríos Silván y Porma, determina de manera importante la estructuración del frente, del mismo modo que condicionó las actividades militares a lo largo de 1937 y la caída del Puerto de San Isidro. La configuración de un valle con una anchura media de $500 \mathrm{~m}$ flanqueado por los altos y abruptos escarpes que forman la falla de Cofiñal, convierte un ataque frontal en una operación muy arriesgada. Esta configuración orográfica llevará al ejército sublevado a realizar una maniobra envolvente desde Maraña, dirigida por Muñoz Grandes, y desde la línea Vegamián-Lillo la Agrupación Lillo, dirigida por Ceano Vivas, cuyo objetivo era evitar los puntos más fortificados del frente y sorprender la retaguardia republicana.

Las acciones comenzarán el día 20 en el puerto de Tarna, que es objeto de una maniobra envolvente desde el puerto de Ventaniella, que cae el día 26 de septiembre. Las operaciones en Lillo darán comienzo el día 24 con la llegada al anochecer de 40 camiones con soldados, si bien los republicanos lo relacionan con el relevo y refuerzo de las tropas de la zona ${ }^{63}$. Viendo el ataque sistemático del

\footnotetext{
${ }^{61}$ ALVAREZ OBLANCA et al., op.cit.

62 SALAS LARRAZÁBAL, op.cit.

${ }^{63}$ Diario Avance, 24-09-1937:2.
} 
Eduardo González Gómez de Agüero y Víctor Bejega García

Ilustración 2. Maniobra sublevada sobre San Isidro (elaboración propia).

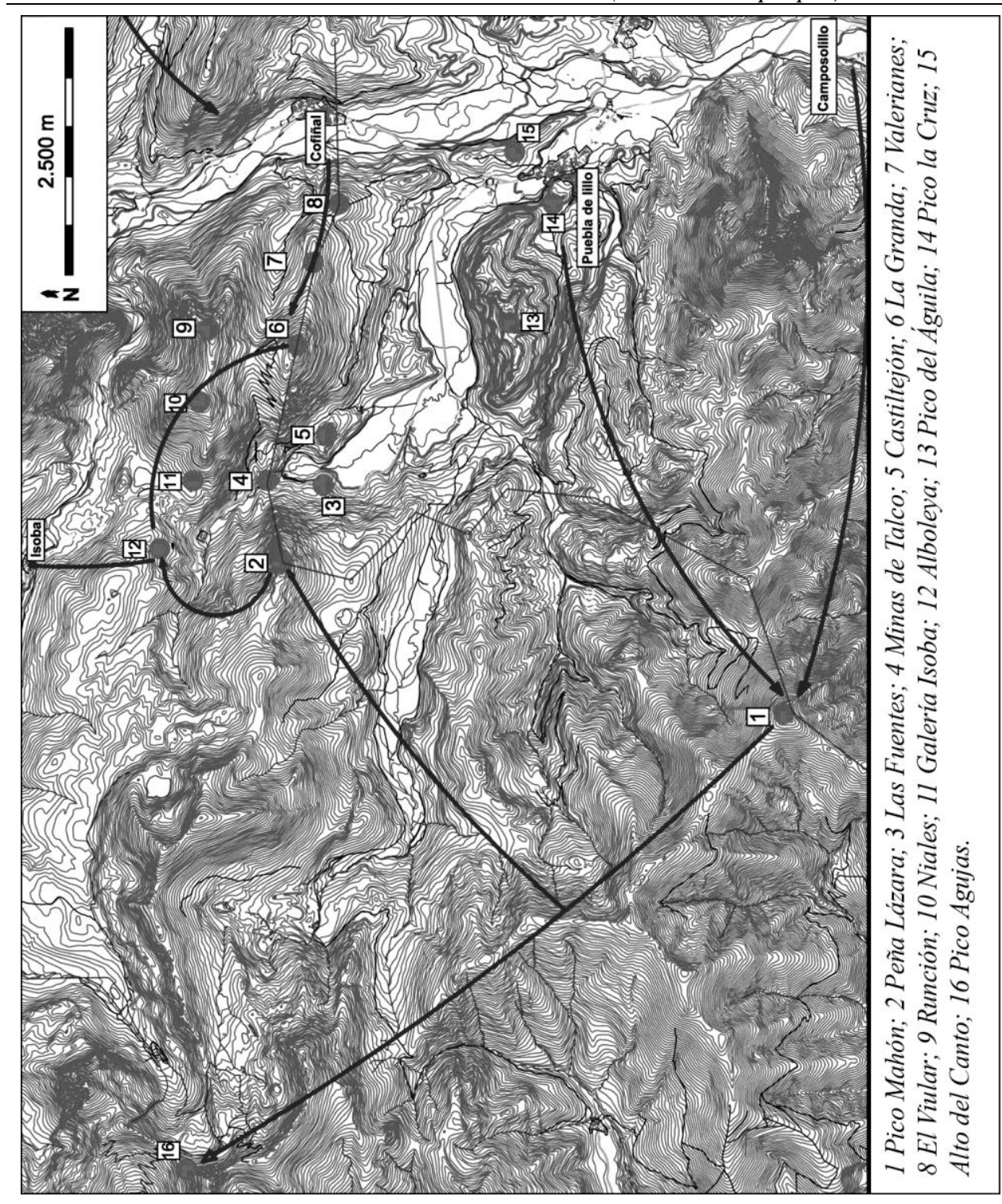

ejército franquista al frente astur-leonés a lo largo de septiembre, los republicanos solicitan refuerzos para sus líneas. Probablemente esperaban un ataque por la carretera de Isoba o por la de Cofiñal, y no una maniobra envolvente como la que 
se realizó. De hecho en el Pico Mahón, lugar por donde se romperá el frente, la fortificación está formada por parapetos y trincheras, sin construcciones de una envergadura destacable ${ }^{64}$. El día 28 de septiembre, unos días después de que comenzara la operación, la prensa republicana hace referencia a la tranquilidad en San Isidro y a la realización de trabajos de fortificación, lo que vendría a reforzar esta hipótesis ${ }^{65}$.

Las tropas dirigidas por Ceano atacaron desde Camposolillo y Lillo el día 26 de septiembre, rompiendo el frente en Pico Mahón (Ilustración 02) el día $27^{66}$; aunque el Batallón gubernamental 250 aguantará hasta el día 29, se verán obligados a replegarse hasta el puerto de Vegarada, mientras los sublevados conectarán el Pico del Águila con Valporquero ${ }^{67}$. Este ataque parece que fue mucho más violento que los realizados en Tarna, alternando oleadas de aviación y de tropas de choque ${ }^{68}$. Al mismo tiempo las tropas de Muñoz Grandes toman el día 29 el Pinar de Lillo llegando a la carretera que une Tarna con Cofiñal ${ }^{69}$, pueblo que es tomado al día siguiente $^{70}$. Es probable que esta maniobra se debiera en gran medida a la ayuda prestada por un vecino de Puebla de Lillo que les mostró el paso por el Collado de Ferreras $^{71}$.

Una vez rota la primera línea de resistencia republicana, el avance de las tropas de Ceano se produjo rápidamente por las cumbres de la sierra de Valporquero, que son tomadas completamente el día 30 de septiembre después de duros combates con los republicanos, que aprovechaban las cuevas existentes en la zona para intentar frenar al enemigo ${ }^{72}$. El día 1 de octubre toman Pico Agujas e intentan romper el frente en San Isidro ${ }^{73}$.

En cuanto a las tropas que avanzaban por la derecha de Lillo, una vez tomado Cofiñal, avanzaron por las posiciones de Valerianes y el Viular, que se situaban por

${ }^{64}$ GonZalez Prieto, L.A.; ARgüElles, J.L.; PAlomares, L. (2007). La Maginot Cantábrica. 50 rutas por escenarios de la Guerra Civil en Asturias y León. Madrid: Desnivel, p. 239.

65 Diario La Vanguardia,29-09-1937:4.

${ }^{66}$ GARATE, op.cit.

${ }^{67}$ En los partes de Guerra y en algunas noticias de prensa aparecerá como Malporquera.

${ }^{68}$ Diario Avance, 30-09-1937:2.

${ }^{69}$ Según parece habría sido evacuado el 25 de abril.

${ }^{70}$ Diario $A B C$, 30-09-1937:7.

71 “Aquí la maniobra final de la guerra fue cuando los envolvieron subiendo por las cumbres, que fue uno de este pueblo, de Lillo, quien les mostró el paso" Laudelino Sánchez, 07-09-2011.

${ }^{72}$ Diario de León, 01-10-1937:6.

${ }^{73}$ Diario La Vanguardia, 01-10-1937:3. 
encima del pueblo, asegurando el valle del Porma ${ }^{74}$. Es muy probable que a la llegada de las tropas rebeldes estas posiciones ya se encontraran vacías, como sugiere la dispersión de materiales documentados en las mismas. La ruptura del frente por el Pinar de Lillo las habría hecho vulnerables al tomar el enemigo su espalda, por lo que los republicanos se habrían replegado con un posible fuego de cobertura, a juzgar por los casquillos documentados.

Un temporal obligó a detener las operaciones que se reanudarán el día 3 de octubre, contactando las tropas de Ceano con las de Muñoz Grandes en Cofiñal después de ocupar La Granda ${ }^{75}$, así como Niales y Runción, además de Peña Lázara, Isoba y Alboleya que son ocupadas dos días antes ${ }^{76}$.

Igual que pasaba con las posiciones de Cofiñal, es muy probable que estas estuvieran abandonadas a la llegada de las tropas de Ceano. De hecho, no hay referencia en los partes de Guerra, ni en la prensa del momento, de enfrentamientos en este sector, lo que también explicaría el rápido avance franquista. En este mismo sentido iría la descripción del abandono de la posición avanzada de Castiltejón ${ }^{77}$. Según parece, esta posición sería tomada el 29 de septiembre por una columna dirigida por el comandante Agulla. Por lo tanto, estas posiciones serían abandonadas al poco de romper el frente, entre los días 27 y 29. Durante la excavación no detectamos signos de lucha, además de recuperar fragmentos de huesos roídos por carroñeros, lo que indicaría su permanencia a la intemperie. A este respecto, se recogieron siete vainas en los extremos de un pozo de tirador en "T", agrupados cinco en el brazo izquierdo y dos en el derecho, siendo los únicos restos que nos indiquen un enfrentamiento en los últimos momentos de ocupación. Todos ellos pertenecen a casquillos de 8x50 Western para Lebel, y se encontraban orientados suroeste-noreste, en dirección a Cofiñal. Si bien es muy difícil determinar a que corresponden estos disparos, creemos que no serían para frenar un ataque, sino más bien como fuego de cobertura o para intentar derribar algún avión, algo habitual como veremos posteriormente.

${ }^{74}$ Diario de León, 01-10-1937:6; Diario ABC, 01-10-1937:8.

${ }^{75}$ Diario de León, 04-10-1937:6.

${ }^{76}$ GARATE, op.cit.

GONZALEZ PRIET et al., op.cit.

77 "El Pico del Águila es una de las antenas de la muralla de León. A muy pocos metros de ella tenían los rojos una avanzada, en la que han permanecido fortificados más de un año. Cuando hace días rompimos la línea enemiga, la posición fue abandonada más que deprisa. Los rojos se vieron envueltos y la abandonaron. Sus alambradas, sus refugios, sus parapetos, de nada sirvieron a los que no se atrevieron a resistir en ella, que esquivando el ataque huyeron sin resistir la maniobra [...]" (ABC 1-10-1937: 8). 
Por lo tanto, las tropas desplegadas en el sector de Lillo se habrían replegado al romper los sublevados la línea de frente, seguramente con el fin de presentar una segunda línea de defensa. Además, el haber mantenido la posición hubiera significado el aniquilamiento de las fuerzas republicanas, ya que les hubieran sorprendido por la espalda, dejando bolsas de resistencia fácilmente reducibles. Después de este repliegue, el día 5 de octubre se reorganiza otra vez el ejército republicano, quedando San Isidro bajo la defensa de la 194 Brigada al mando de Celestino Uriarte Bedia y fijados en la Venta de San Isidro ${ }^{78}$.

El día 4 de octubre Ceano llega al Puerto de San Isidro, y el día 5 lo toma definitivamente, avanzando hacia Asturias. En un primer momento el avance rebelde no se encuentra con una importante resistencia, aunque esto cambiará a partir del 6-7 de octubre. En estos días, y tras el peligro que corren las posiciones de Tarna de ser rodeadas, se producirá un ataque republicano de las tropas que ocupaban estas posiciones, sin que tengan un resultado positivo.

$\mathrm{Al}$ mismo tiempo se producirán ataques gubernamentales en la Loma del Ajo, aunque no conseguirán su objetivo, perdiendo las posiciones de Casteloños, desde donde se inició la ofensiva ${ }^{79}$. En esta batalla jugó un papel fundamental la aviación, que bombardeó intensamente las posiciones republicanas, llegando incluso a afectar a sus propias líneas ${ }^{80}$. El ataque republicano se recrudecerá el día 8 con las Brigadas 186 y 194 avanzando sobre la Loma del Ajo, Casteloños y el Pico Agujas $^{81}$, que, debido a los ataques de días anteriores, habían fortificado los rebeldes. La maniobra la realizó el Batallón 219, que atacó el flanco, y el Batallón 250 que consiguió tomar varias lomas de la parte alta del Pico Agujas ${ }^{82}$.

En esta batalla se derribó un caza italiano que escoltaba varios bombarderos y que estaba pilotado por un sargento canario que tuvo que aterrizar de manera forzosa, como recordaba Laudelino y como aparece reflejado en la prensa del momento. Es probable que este aparato correspondiera a un Fiat CR. 32 con base en León y que, además de ametrallar posiciones enemigas, se dedicaban a escoltar a los HE-45 y Aero- 101.

El día 9 se producirá una ofensiva de los sublevados sobre las posiciones ocupadas el día antes por los republicanos. Estas continúan al día siguiente, cuando

\footnotetext{
${ }^{78}$ SALAS LARRAZÁBAL, op.cit.

${ }^{79}$ Diario de León, 08-10-1937:6.

${ }^{80}$ Diario Avance, 08-10-1937:2.

${ }^{81}$ Pico Buján en la prensa y los partes.

82 Diario Avance, 09-10-1937:2; Diario ABC, 10-10-1937:3.
} 
ocupan definitivamente Peña Agujas y Catelloños, obligando a la retirada de los republicanos a Castillones y al Puerto de Vegarada. Ese mismo día realizó una visita al sector de Lillo-Riaño el General Franco junto el General Dávila y el General Aranda ${ }^{83}$ para seguir las últimas maniobras en tierras leonesas y ver el terreno que tanto les había costado ocupar y que abría las puertas al final del Frente Norte. Entre los días 11 y 12 de octubre el bando sublevado derrotará a las tropas republicanas en el sector de San Isidro tomando el Pico Toneo ${ }^{84}$ y concentrando la resistencia gubernamental en León a una pequeña franja entre el Puerto de Pajares y el de Vegarada ${ }^{85}$.

\section{ALIMENTACIÓN Y ABASTECIMIENTOS.}

Uno de los principales elementos que van a caracterizar la Guerra Civil en el frente astur-leonés son los problemas de abastecimiento de las tropas republicanas. Pocos meses después de producirse el levantamiento militar, el Comité Regional de Defensa de la República en León ya se hace eco de este problema ${ }^{86}$. Como ya comentamos, van a ser normales las incautaciones de ganado por parte de las tropas gubernamentales en los primeros meses de conflicto ${ }^{87}$. Incluso en el diario republicano Avance (16-05-1937: 6) se hace referencia al negocio que supone la toma de nuevas posiciones debido a la incautación de nuevas cabezas de ganado ${ }^{88}$.

Estos problemas con la alimentación los hemos podido documentar en las excavaciones realizadas en el Cerro de Castiltejón. Durante estos trabajos recuperamos un gran número de restos óseos, principalmente de bóvidos y ovicápridos, correspondiendo la mayoría de estos huesos a pequeños fragmentos de costilla. Esto nos indica la utilización de la carne como complemento en guisos, permitiendo alimentar a un mayor número de personas con menos cantidad de ésta. En estos guisos acompañaría a un ingrediente principal que solía ser el arroz, las legumbres o las patatas y la pasta.

${ }^{83}$ Diario de León, 11-10-1937:6.

${ }^{84}$ En los partes y la prensa aparece como Táfico, Tálico o Tático.

85 Diario de León, 12-10-1937:1; 13-10-1937:2; GONZALEZ PRIETO et al., op.cit.

${ }^{86}$ Fernandez FernandeZ, P.V. (1989-1990). «El Boletín de Guerra del Frente Popular de León, en 1936». Tierras de León, $n^{\circ} 77-78$, pp.153-173.

${ }^{87}$ Diario de León, 18-09-1936:6; 28-11-1936:5; Diario Proa, 24-11-1936:6.

88 "[...] Por otra parte cada avance que se haga en los puertos es prácticamente un excelente negocio para nuestras fuerzas. Sobre aquellos pastizales salvajes existe la mayor riqueza ganadera de nuestra provincia. Y no hay kilómetro que se le quite al enemigo que no nos deje un buen número de cabezas de ganado reduciendo a la par el terreno que el enemigo tiene para sostener su ganado trashumante" (Avance 16-05-1937: 6). 
Esta situación contrasta con el abastecimiento en la zona sublevada, donde, aunque existieran restricciones y problemas de alimentación propios de un estado bélico, controlaban en la retaguardia amplios territorios que eran productores de alimentos básicos que le permitían un mejor abastecimiento. Así, el control de la meseta les garantizaba una importante producción agrícola y ganadera. Por otro lado, Galicia, además de abastecer al frente astur-leonés de patatas, era una de las zonas de mayor producción de conservas de pescado de Europa.

En cuanto a las latas de conserva, los restos documentados no son muy elevados, lo que podría estar reflejando estos problemas de abastecimiento. De hecho, en el Diario Avance del 24 de septiembre de 1937, al hacer un inventario del botín realizado al atacar Busdongo, hacen referencia a latas de conserva y raciones de pan junto al armamento capturado, algo muy poco habitual en este tipo de partes. La utilización de conservas por parte del ejército presenta toda una serie de ventajas a la hora del avance de las tropas y de la toma de posiciones, ya que la conserva permite al soldado portarla encima sin la necesidad de realizar un tratamiento térmico para su consumo.

Las diferencias de abastecimiento de los dos ejércitos no van a existir únicamente a nivel alimenticio, sino que también se van a reflejar en el armamento y la vestimenta. El día 30 de septiembre de 1937 el Diario Avance recoge el ataque sublevado a Pico Mahón, donde podemos leer una frase que resume perfectamente estas diferencias de material: "Numerosos contingentes de tropas de choque, apoyados por inusitado lujo de material, presionaron furiosamente sobre las líneas republicanas de Pico Mahón”. La munición, fabricada antes de 1920, correspondería a varios tipos de armas excedentes de la I Guerra Mundial, y muchos cartuchos con más de dos recargas ${ }^{89}$. Mientras tanto, la munición de los sublevados corresponde con proyectiles fabricados en la década de 1930 procedentes de las fábricas alemanas para K98, el arma de élite del ejército alemán. A todo esto habría que unir el importantísimo apoyo alemán e italiano con la aviación y la artillería.

Durante la excavación de Castiltejón recuperamos dos peines de Mauser alemán que llegarían al ejército republicano fruto de la captura de armas que se produce en ofensivas como la de mayo del 37. Estas capturas de material parecen ser muy habituales, como se desprende de las diferentes noticias de prensa y partes de guerra.

\footnotetext{
${ }^{89}$ Se han documentado tres casquillos de 8x50Rmm para Mannlincher M.88/93; nueve casquillos de $8 \times 50 \mathrm{~mm}$ fabricados por Western para Lebel y un casquillo 7x57mm para Mauser Mod.1893.
} 
En cuanto a la vestimenta, también hemos detectado ciertos problemas de abastecimiento en el ejército republicano con la presencia de zapatillas con corte de tela, muy típicas de la población civil de la época, y abarcas con suela de neumático, tipo de calzado tradicional de la montaña. En este mismo sentido, se han recuperado dos botones tipo balón, normalmente usados en chaquetones.

\section{CONCLUSIONES.}

Pese a la poca actividad militar que se desarrolló en este sector, su posición estratégica fue determinante en el devenir de la Guerra en el frente astur-leonés. Los dos ejércitos van a prestar mayor atención al mantenimiento de las posiciones que a un hipotético avance, ya que las pérdidas de las mismas podrían tener importantes consecuencias. Esto se va a ver reflejado en la fuerte fortificación que desarrollan los republicanos, así como en la reacción sublevada reforzando líneas ante la ofensiva de mayo de 1937. En este contexto podemos encuadrar el ataque sublevado en septiembre de 1937, ya que la caída del puerto de San Isidro permitirá el avance de las tropas por la costa y aislar a la resistencia en la zona central de la cordillera, lo que facilitará el acceso de los sublevados a Gijón.

La principal obsesión de los republicanos era fortificar los accesos por carretera al Puerto de San Isidro, por lo que van a planificar una tripe línea defensiva formada por puestos avanzados, una línea continua de frente aprovechando los altos escarpes de la Falla de Cofiñal, y una tercera línea fortificando puntos estratégicos. Por lo tanto, la fortificación republicana en el Valle del Silván se encontraría muy bien estructurada, aprovechando las posibilidades orográficas que ofrece el lugar. Su eficacia va a quedar demostrada con la imposibilidad de tomar estas posiciones militarmente, siendo capturadas una vez abandonadas al romperse el frente por los flancos debido a su mayor debilidad.

Por otro lado, aspectos como las diferencias en el abastecimiento de armas y suministros existentes entre los dos ejércitos, así como la mejor organización y planificación táctica de las tropas sublevadas, van a ser decisivos en el desenlace de la Guerra en este sector.

La intervención arqueológica sobre escenarios bélicos abre nuevas vías de estudio para abordar aspectos poco tratados como la organización y desarrollo del frente o la vida cotidiana. Por otro lado, el estudio combinado y crítico de fuentes arqueológicas con documentales y orales pueden dar una nueva visión de la Guerra Civil desde una perspectiva "más humana" de las personas que lo sufrieron. Con este trabajo pretendemos establecer un punto de partida que permita en el futuro abrir nuevas vías de investigación. 